\title{
Investigate the Reasons Why Variety Play in the Yuan Dynasty Flourished from the Angle of Gender Holism
}

\author{
Xiaoyan Liu \\ Music Department of China -West Normal University, Nanchong,Sichuan Province
}

Keywords: Intelligentsia, Brothel Prostitute, Mode of cooperation between mem and women

\begin{abstract}
In academic field, there are a great number of viewpoints about the prosperity of Variety Play during the Yuan Dynasty. This paper on vision of Gender Holism will attempt to reveal the cause of the prosperity of Yuan Drama by methods of Anthropology Research.
\end{abstract}

\section{Preface}

Some experts have probed into the reasons why did the Yuan Variety Play flourish. ZhengZhenduo once said:"oppression of national minority is too heavy and the status of the Hans is much lower than the Semu nationality. What are called savages are those who are rode roughshod over at any time. Even those intelligent people who secured an official position would last in a humble position forever, and there is little possibility for them to promote. Therefore, they indulge in amusement in order to seek the comfort of sense. In this way, composers fritter away lament and hearers forget their agony."[1] in Illustrations of the China Literature History. Hereafter, ZhouYibai said:"the main contradiction in the society at that time was the contradiction between the Yuan and the Hans. The former tyrannically abused their power and the later suffered oppression. Writers created according to the reality, diverging thinking or seeking hope, which was the main reason why the Yuan Variety exsits." [2]in The Long History of Chinese Drama. This two masters believe the source of boom of theYuan Variety Play is need of resisting ethnic discrimination and class oppression. militant and popular arts are able to express call od times and appeal of people. What's more, some scholars believe rulers of the Yuan adopt the policy of racial discrimination and close the imperial examination. Many Han intelligentsia chucked the opportunity of being officers away, then the social status of them declined dramatically, fallling to accompany with brothel Geisha. HuShi of the Ming Dynasty believed the policy of racial discrimination and oppression applied by the rulers of the Yuan Dynasty frustrated the Han intelligentsia. Only used their talents to compose the Variety Play, can they combine their emotion in songs [3]. XuFuming clearly pointed out that scholars who degenerated to be worldly were close to lower class people and opera artists, because of their lower social status and various sufferings. ......they learned and promoted mutually, which heightened production of theYuan Variety Play [4]in The Yuan Opera Art. Several The History of Chinese Literature published after the founding of new China, GuXuejie and WangJisi also approved this view. The point that closure of the imperial examination promoted the boom of the Yuan Variety Play is a very preponderant perspective in the academic world at present. What's more, the view of favour of rulers, the view of loose ideological and political environment, the view of prosperous economy of cities and so on are popular.

Riane Eisler classified various civilized configuration of human beings into two fundamental social pattern in his masterpiece The Chalice and the Blade. The first one is the pattern of rulers, which is the social pattern of patriarchy and matriarchy society--half people's status is higher than the another half; the second is partnership model. In this kind of society, the base of social relation is relationship principle rather than scalar principle. In this model, we start from the most basic difference of both sexes--difference is not distinction of good and bad.[5] This paper would start from the perspective of cultural anthropology, apply the thoery of Gender Holism of American Anthropologist Riane Eisler, and investigate two group-Yuan intelligentsia and brothel Geisha who involve in the cause of the boom of Yuan Variety Play under special social and historical environment. This paper would abandon intrinsic level threshold, construct relationship cooperative 
mode between men and women in the field of drama creation, and try to reveal factors which impel the development of Yuan Variety Play from a brand new angle.

\section{Exposition of Special phenomenon of social formation}

As we know, the Yuan Dynasty is a unitary multinational state built by minority nationality Mongolian nationality,and it characterizes diffrient traits of central plains dynasty centralised with the Han nationality.

At first, the social status of women in the Yuan Dynasty improved much compared with with Tang,Song and even Liao and Jin Dynasty.YeZiqi in the Ming Dynasty once said:"the Yuan Dynasty is traceable from the desert, and their customs are unsophisticated.The king and minister share the same name. Although later taboo methods were issued, they were just nonsignificant. At first, the Yuan Dynasty didn't respect the methods much, so they were not popular among scholar-bureaucrat[6]. As a Nomad Of The North, when they first marched into the Central Plains, influence of feudalism ethics morals to them was less than the Han. They upheld nature in daily life and marriage customs." reign of Mongolian nationality heavily shocked Confucian culture in the Han nationality region. As a form of arts, Mongolia customs gave legal protection to the Han culture. Because of historical reasons, Mongolia women, the ruler class, occupy important socioeconomic status, which promoted status of women in the Yuan Dynasty in general. "[7]Status of women in the Yuan Dynasty relatively improved compared woth Song Dynasty. HuangZongkai once pointed out : the Yuan Dynasty is a time which witnessed the highest status of women in the feudal society of the late China. The social position of women in the Yuan Dynasty is also higher than later Ming and Qing Dynasty.

What's more, intelligentsia in the Yuan Dynasty gave up arrogant posture, associate with humble a prostitute and Geisha, and exchange poetry. XiaTingzhi in the Yuan Dynasty recorded in The brothel, Bead curtain show that his first name is Zhu, and he ranked fourth. His dramas were best in the world. $\mathrm{He}$ was expert of all kinds of dramas which involve kings, famale roles and scholars. $\mathrm{HuZishan}(\mathrm{ZhiYu})$ once gave Intoxicated Dongfeng Qu to Yun: "Brocade Chinese asters over the river, and dress cashmere with seas, montains and pearl. Whenever the moon was pale and light, it obstructed falling flowers and muds. Leisure was extended, presenting moring clouds and evening rain. "[8]FengHaisu also composed a poem called Partridge Sky and gave it him. "Rely on the west wind and the can see mansion in distance.Flying warblers peep my face and swallows bow their heads. Feelers of shrimp are thin and decorative patterns of tortoise flow.Red fog and colorful clouds close. sunset clouds over the sea are like belts and the moon is like a hook. The night engulfed the rain in the west mountains, never touching little sorrow of human beings.'[9] As a famouse actor, Bead curtain show associated deep with many intelligentsia in the Yuan Dynasty, such as GuanHanqing,LuZhi,FengZizhen, WangJianqiu and ect. They often composed poem to gift anf answer others. Some these intelligentsia were in high social positi,some were very rich and some were very talented. Thses men with high prestige gathered happily with humble entertainers, which spreaded to be a beautiful stories.

Moreover, in lasting dramas, there are some works about the angle of womens, which presents concerns about marrige and discuss women's fate. YangXianzhi, ShiJunbao anf ShangZhongxian are representatives. Female characters are stubborn, sagacious and independent. They are never submissive, but fight against darkness of society actively. New female characters appear in the dramas. They are bold and shrewish, with distinct personality and kindness of traditonal women. For instance, the whore ZhaoPaner in the The Rescue of a Courtesan apply little tricks to rescue SongYinzhang, utilizingZhouSe's mercenary and sensual weakness, when her sister is raped by bully ZhouSe, which perfect the marrige of SongYinzhang and scholar AnXiushi. Remarried widow TanJier in the Pavilion WangJiang, she dresses up as a fish women and sets foot into danger, the she cheated to get golden medal and document which symbolizes power of YangYanei when she is about to be raped by celebrated YangYanei and her humble husband has nothing to do.at last, Yang is justly punished. Maidservant HongNiang in the The Romance of West Chamber is be pretty,intelligent and 
quick-witted. Confronted with obstacle of feudal influence and retraction of YingYing, she ingeniously circles round Old lady and prime minister who represent feudal power, which accomplishs love of ZhangSheng and YingYing. These female characters are totally different with those before, for they would never accept arrangement of fate willingly. The image possesses traditional virtue of kindness and chivalrous character. They fight against vicious powerin the society cunningly and break cage of feudalism with their own wisdom. Eventually, they harvest happy love and present satisfactory endings to the public.

\section{Analyze social phenomenon of the Yuan Dynasty with Gender Holism and two fundamental models}

\section{Meet the conditions of cooperation of men and women}

Customs in the Yuan Dynasty paid much attention on practicality, and the rulers protected and utilized groups with specialty, such as worker, caftmen, doctors,monks and Taoist. Similarly,the knowledge about singing and dancing of artists of the Yuan Variety Play and Geisha satisfy entertainment need of rulers of Yuan Dynasty, so rulers protected them in their limits.Besides, this specialty corresponded to customs of the Yuan Nationality who like singing and dancing. What's more,extravagant trends in the central plains for a long time and urban civilization which thrived abnormally prosperity emphasis social influence of artists of the Yuan Variety Play and Geisha.

Compared with this, some people's lifestyle which depended on reading confucian classics and spreading Confucianism to seek officer position suffered a lot. At first, they wandered from place to place because of changing dynasty, then they faced the long -time closure of imperial examination. When Yuan Nationality marched into the central plains, the ruler despised education, which insulted them and deprived their social influence as before, falling to the bottom of the society. Dayi Sequency of ZhengSixiao noted:"ranking methods: from the first to the tenth are ministers,officers, monks, Taoists, doctors, workers,hunters,farmers, Confucian scholars and beggers. They all have the governance." [10] XieFang described in Preface of Sending FangBozai to Sanshan that in the traditions of the Yuan Dynasty, there is ten levels. The first is ministers and the second is officers. The former one is nobler than the latter. The noble are beneficial to the country. The seventh to the tenth is craftmen, prostitutes, Confucian scholars and beggers. The latter are humbler than the former. The humble are useless to the country.[11] Intelligentsia were never well-beloved and fell to the bottom of the society. To seek lifehood, they had to engage in occupations which they despised before and which demaded labour force, such as soldiers,craftmen, merchants,doctors, and augurs.

In this way, the social position of intelligentsia and Geisha gradually closed, "the need of intimity increases andneed of power decreases. This was a relatively peaceful world, and our achivements are remarkeble, which indicates certain prosperity."[12] The conditions for Yuan Variety Play boom--affinity between intelligentsia and Geisha increases, which becomes the presupposition of cooperation of men and women.

\section{The change of consensus of mainstream society}

Cooperation of men and women is fellowship built on both sexes and based on equality. There never lacks excellent examples of this kind of relationship in the history. For instance, BaiJuyi's rhesis in Lute Song we suffered similar fate, and since we met,we had no need to know before. He treats a Geisha who plays lute as hisfemale intimate. Famouse lyricist LiuYong in the the Northern Song once song:'I'm lucky to get a beloved one, therefore I would seek her; I depend on flowers and say my deeds cheerfully. Youth is short, but I trun pursuit of fame to intonate. .'[13] But the intercourse in soul between intelligentsia and Geisha was viewed female and frail by mainstream society dominate by men. The meet of intelligentsia and Geisha was blamed by family and society. The large hierarchical gap between them made then dare not to break the baseline of public opinions; therefore, they had to bury romantic affairs of them in scacia poetry as a outsider's view. Lyricist LiuYong mentioned before failed several times in the imperial examination, then he tried again, when King 
SongRenzong read the list, he crossed out LiuYong's name. Liu said:'I would intonate instead seek fame.'[14]He failed another time. Emotional trigger intelligentsia and Geisha is soul connections moved by similar scenes and depressed by officialdom, because they still could not get rid of the boundedness that treat Geisha as accessory of men. Advocating masculine and active statecraft is in fact a ruling relationship built upon hierarchy in which the status of men is higher than women's in the men- dominant society.

The reign of the Yuan Dynasty in the ideological sphere is relatively looser than the former and later dynasties. In the united and stable country, the territory expands and each nationalities intercourse to the greatest extent. To meet development needs, the Yuan Dynasty carry out the policy of opening and advocating freedom of religion belief, therefore Confucianism,Buddhism,Taoism,Muslin,Christianity, and Shaman decelop fairly and freely. The social model characterizes tender and femaler value. Except various social occupations mentioned before, intelligentsia in the Yuan Dynasty would become writers of reading clubs. They compose scripts for entertainers and creating dramas turns to be a livehood. In Brothel Sequel ZhuJing once said:"'at the begining of our Yuan Dynasty, our domain linked seas and sky. But the adherents of a former dynasty such as DuSanren, BaiLangu and GuanJizhai were never interested in politics, lingering moon and scenery, which is scoffed by officers." [15]Mongolian nationality emphasizes on practicality and advocates the pure nature. They conqure the world by using bows and horses with ferocity of lower stage of social development, bursting into Central Plai with perfect feudality and rigorous morals and shocking monarchical, patriarchal,husband power traditions dominated with the Han nationality. Social customs reenter muddle state of division-transition-recombination, which influences world view of intelligentsia in the Yuan Dynasty with two results. The first one is hedonism indulging in entertainment. The second is seclusion hiding from earthliness. As the factor of advocating masculine culture, the dream of managing state affairs declines and exploration of pleasure and seclusion increases. The thinking pattern of despising Geisha is broken, and soul association between intelligentsia and Geisha is never excluded by the society. Intimacy overweights power, which meets the condition of cooperative society pattern of men and women in the cultural development processes of human beings.

\section{Conclusion}

At present, guiding ideology is full of power struggles among men and nationalities in the history textbook in most schools. History is dates of wars, names of kings and generals, and military engineering,palaces, religious facilitiesbuilted by them, and valiant records of killing same species cruelly. Master LiangQichao,advocator of New History disclosed four disadvantages and two weakness in the development of Old History in China. Four disadvantages were knowing court rather than the country, knowing individules rather community, knowing antiqueness rather than current affairs, and knowing facts rather than dreams. Two weakness were people can narrate rather than innovate and they can inherit rather than creat. Because of four disadvantages and two weakness, a colorful history is written to be genealogy of kings and Generals,epitaph and Wax Institute to. Liang's words not only reflect Chinese ancient history is not genealogy of kings and Generals, but also vray aesthetics of violence and the history of hierarchy dominated with men.

Political atmosphere in the Yuan Dynasty is frozen and despotic, but ideology id opening and free, which reduces power factors of intelligentsia in the Yuan Dynasty and increases factors of affinity. This shelters approaching of intelligentsia and Geisha in consensus. Intelligentsia walk from the view of outsiders to insiders in creating Variety Play and interact with humble Geisha in soul actively. Intelligentsia and Geisha complete assimilation of these two social groups and break separation of social estate. They not only abandon contempt laboring people at the botton of society, but also discrimination to occupations of Geisha and prostitutes. They wield their talents of managing state affairs in arranging disorganized and funny dramas and adopting splendid passages with profound 
thoughts and times characteristic, which produces another climax of history of Chinese civilization-the prosperity of the Variety Play in the Yuan Dynasty. 


\section{References}

[1] ZhengZhenduo:Illustrations of the China Literature History,The people's Literature Publishing House, 1957 Edition, p.p638.

[2] ZhouYibai: The Long History of Chinese Drama,Shanghai Century Publishing Group, 2007 Edition,p.p192.

[3] .HuShi(Ming Dynasty): chapter 4 of Boat of Real Pearl, Series integrated preliminary,Zhonghua Book Company,1985.

[4] XuFuming:The Yuan Opera Art,Shanghai literature and Art Publishing House, 1981 Edition, p.p14-15.

[5] Riane Eisle:The Chalice and the Blade translated by ChengZhiming,Beijing: Social Sciences Academic Press,2009, p.p15.

[6] Yeziqi(Ming Dynasty):CaoMuzi,chapter 3 of Miscellaneous Business Articles,Zhonghua Book Company, 1959, p.p8-50.

[7] WangJianhong: Women's Social Economic Status in the Yuan Dynasty,Hebei Normal University,2003.

[8] HuangZongkai:A Brief Discussion on the Status of Women in the Yuan Dynasty,Journal of Guangxi University for Nationalities(edition of social siences),2001(02).

[9] ShiZhecun:Partridge Day: Curtain Show to prostitutes.The song and Yuan Dynasties Poetry edited by ChenRujiang,Shanghai Bookstore Publishing House.

[10]XieFangde(Yuan Dynasty), collections of XieDieshan edited by WangYunwu.Series integrated preliminary,Commercial Press, 1936.

[11]XieFangde:Files oF Song Dynasty 8217, Shanghai:Shanghai Lexicographical Publishing House, 2006.

[12]David Mclellan(America),Power: the Inner Experience,New York, Ovenden Press,1975,p.p 320-321.

[13]LiuYong(SongDynasty):Crane cupola.

[14]WuZeng(Song Dynasty): Books of NengGai Study, chapter 16,Shanghai: Shanghai Ancient Books Publishing House, 1979.

[15]XiaTingzhi(Yuan Dynasty):Collections of the Brothel, ChenLiangyun: Theories of Composing in Successive Dynasties of China,BaiHuaZhou literature and Art Publishing House, version 2002.

[16] ShiGexin:Learning from the west in the early 20 th century and fundation of New Historiography in modern china. 